\title{
BOVINE LYOPHILIZED GRAFT (BLG): HISTOLOGICAL ANALYSIS ON BEHAVIOR IN HUMANS AFTER 49 MONTHS
}

\author{
Carlos Roberto Galia',2, Giuseppe De Luca Júnior ${ }^{3}$, Luiz Müller Ávila³, Ricardo Rosito',4, Carlos Alberto Souza Macedo,2
}

\section{ABSTRACT}

Objective: To analyze the histological behavior of bovine lyophilized grafts (BLG) produced according to a protocol developed by the first author, in humans over a 49 -month period by measuring the graft/bone neoformation ratio in relation to the total mineralized area. Methods: This was a case series involving 12 patients: eight females (66\%) and four males (34\%), totaling 13 biopsies. BLG was used, and surgical reintervention was subsequently required during the period 2000 to 2011 . The slides produced were stained with hematoxylin-eosin (HE), were analyzed by a pathologist and were digitized for the proposed evaluation. Results: The mean age was 57 years and the mean follow-up was 49 months (range: 6-115). The average proportion of BLG was $42 \%$ (range: $13-85$ ) and neoformed bone, 58\% (range: $15-87$ ) in relation to the total area mineralized. Conclusions: This study demonstrated that the BLG used presented osteoconductive characteristics and biocompatibility. BLG is a therapeutic option that can be used in orthopedic surgery in which bone defects need to be filled.

Keywords - Bone Transplantation; Human; Freeze Drying

\section{INTRODUCTION}

The use of bone transplants in orthopedic surgery and dentistry has become indispensable in many procedures, including revisions of total hip (RTHA) and knee arthroplasty (RTKA) ${ }^{(1-3)}$. Despite its great power of repair, bone tissue does not always respond appropriately when affected by extensive osteolysis ${ }^{(4)}$. In these cases, which are highly prevalent in orthopedics, high quality bone substitutes or other biomaterials that can fill and restore these gaps need to be sought ${ }^{(4)}$. A key factor related to the quality of a graft as a bone substitute is the process of bone formation triggered in the host ${ }^{(5)}$. The biological events responsible for osseointegration are osteogenesis, osteoinduction, and osteoconduction $^{(4)}$. A biopsy is the gold standard method to determine the phenomena occurring in the graft, and radiographic studies provide only a macroscopic view of what happens microscopically.

Different types of bone grafts are currently available for orthopedic reconstruction: autologous, homologous and heterologous - xenogenic -, and may be sterilized and preserved by freezing or lyophilization, among other means ${ }^{(5-9)}$. From the point of view of integration, the autograft is considered the ideal and preferred replacement; however, limitations as the quantity available and the risk of complications - local and systemic, ranging from $21 \%$ to $49 \%$ - are inherent in the intervention needed for its withdrawal, restricting its applicability ${ }^{(1,10,11)}$. The frozen allogenic graft is widely used in RTHA, but is not always available, and despite strict controls, poses risk of transmission of infectious diseases and tumors ${ }^{(6,12-14)}$. Heterologous grafts, specifically lyophilized bovine graft (LBG), are

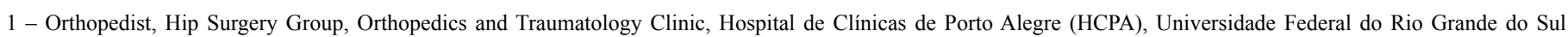
(UFRGS); Professor of the Graduate Program in Surgery at UFRGS, Porto Alegre, RS, Brazil.

2 - Doctor of Surgery, Universidade Federal do Rio Grande do Sul (UFRGS), Porto Alegre, RS, Brazil.

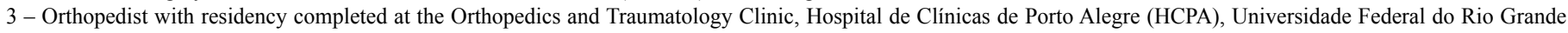
do Sul (UFRGS), Porto Alegre, RS, Brazil.

4 - Master of Surgery, Universidade Federal do Rio Grande do Sul (UFRGS), Porto Alegre, RS, Brazil.

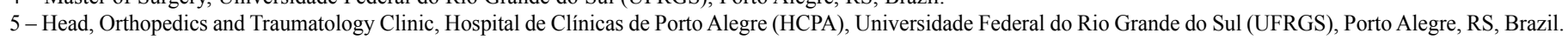

Study conducted at the Hospital de Clínicas de Porto Alegre, Porto Alegre, RS.

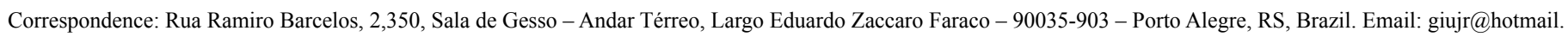
com, galia@portoweb.com.br

Received for publication: 2/12/2012, accepted for publication: 4/12/2012.

The authors declare that there was no conflict of interest in conducting this work 
an option that has been used in several medical areas, due to being easily obtainable, highly available and being highly similar to the human bone ${ }^{(6)}$. To decrease the antigenicity and preserving only the proteinmineral matrix, the LBG is washed, degreased, and decellularized, and is then dehydrated. The bovine bone - raw material for obtaining the proposed graft - has a chemical composition, porosity, size, shape, and biological behavior similar to that of human bone, providing the support structure and osteoconduction, besides providing high content of calcium and phosphorus, which are essential for the neoformation of bone tissue ${ }^{(4)}$. Several studies show this type of grafting experiment in animals ${ }^{(15-19)}$; however, only one performed histological analysis in humans ${ }^{(20)}$. The results of animal studies are hardly applicable in humans because of existing physical and biological differences between them. Thus, studies that will elucidate the behavior of xenografts in humans are of great value.

The fundamental hypothesis of the study, related to the use of the $\mathrm{LBG}$ produced according to the protocol developed by the main author, is its applicability as a temporary structural support that allows osteoconduction and integration of the newly formed bone in deficient areas, promoting satisfactory filling. Our study is justified since there is little detailed information on the subject and the available data are controversial ${ }^{(17-22)}$

This study aims to analyze the histological behavior of this LBG specifically, in humans, during 49 (six to 115) months by measuring the ratio between the graft and bone formation in relation to total mineralized area.

\section{MATERIALS AND METHODS}

The study design is a series of cases that analyzed the histological findings of the LBG produced according to the protocol developed by the main author ${ }^{(11-12)}$, in partnership with Baumer (Mogi Mirim, São Paulo, Brazil) and the Hospital de Clínicas Porto Alegre (HCPA), in human models. The protocol used for this production was based on a modification of that of Kakiuchi et al ${ }^{(23)}$ of Osaka University, Japan, published in 1996. After the modifications, the LBG maintained the chemical (protein-mineral composition) and structural nature of the raw material virtually unchanged, fostering a product that was suitable for its intended use, therefore, with applicability in humans ${ }^{(13)}$.
The group studied consists of 12 patients, totaling 13 samples, collected from July 2000 to January 2011 (mean of 49 months). The LBG was used alone as a graft in cases with significant bone defects - subjectively evaluated by the orthopedic team - resulting from an acute or chronic pre-existing pathology. The inclusion criterion was the need to use LBG in primary surgeries or reoperations that the patients may have undergone. Most of these were in good clinical condition and had no pathology that contraindicated surgery; however, it is worth clarifying: in the patient JARS, due to the large volume of LBG used in the first surgery, it was possible to collect two biopsies from different areas to be counted as two cases; patient SG showed signs of infection in the first surgery, and the RTHA was performed in the same procedure as grafting.

The biopsies were collected at the time of reintervention (due to causes unrelated to grafting).

It is important to emphasize that in no way was any procedure performed with the sole purpose of removing bone fragments for analysis of the behavior of the graft. The follow-up period was estimated from the primary intervention until the time of biopsy. Seven of these were collected using a Yamshidi needle, guided by the image intensifier, with cylindrical shape and measuring approximately $6 \mathrm{~mm}$ long and $2 \mathrm{~mm}$ in diameter, the remaining six, under direct vision with the aid of a biopsy punch or curette. All were immediately immersed in the appropriate fixative during surgery and sent for further analysis according to protocol. In the pathology laboratory, the samples were fixed for 12 to 16 hours in $10 \%$ buffered formalin, with 10 times the volume of the sample. Sequentially, they were washed to remove excess fixative and transferred to a softener, which promoted the removal of calcium phosphate from the bone tissue, using $10 \%$ nitric acid (155 $\mathrm{ml}$ of $65 \%$ nitric acid and $845 \mathrm{ml}$ distilled water) for approximately 24 hours. Afterwards, they were washed with distilled water for six hours to remove the acid and embedded in paraffin, melted at $60^{\circ} \mathrm{C}$, to form blocks. Slides were then prepared from serial transverse sections, that were $200-\mu \mathrm{m}$ on average, with a steel blade, and stained with hematoxylin-eosin (HE). During this process, the HE showed the LBG to be slightly bluish, not matching the areas of osteogenesis that are pink under microscopy (Figures 1 and 2). So, after scanning the images, the areas occupied by each 


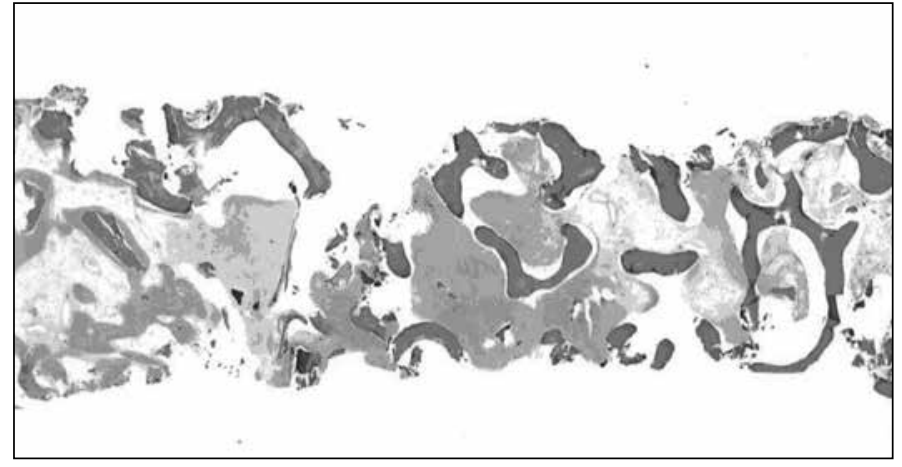

Figure 1 - Lyophilized bovine graft (LBG) stained blue with hematoxylin-eosin (HE). 10x magnification. HCPA 2011.

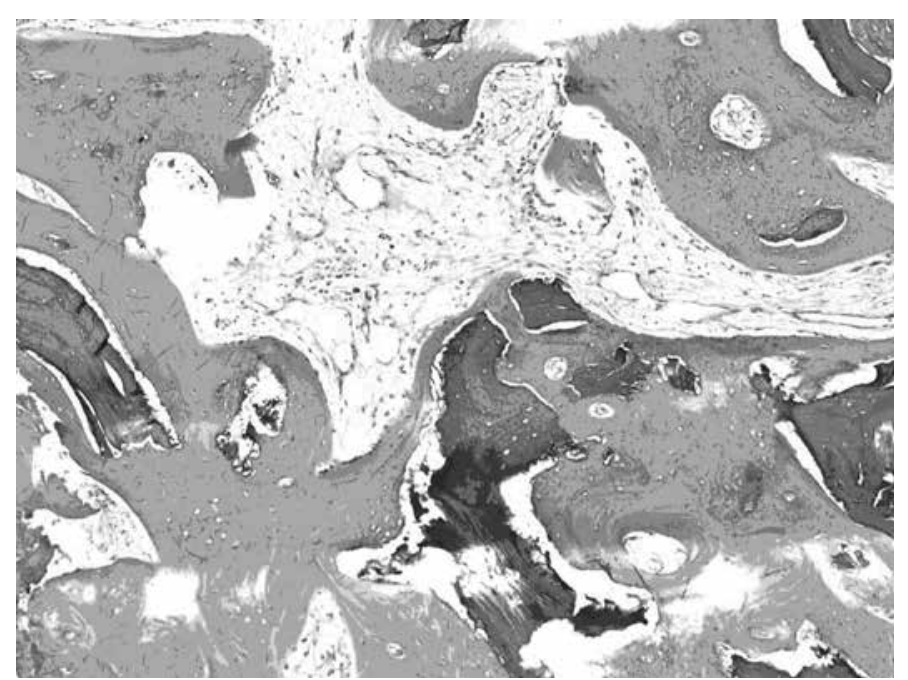

Figure 2 - Blue areas denote the lyophilized bovine graft (LBG) stained with hematoxylin-eosin (HE). 100x magnification. HCPA 2011.

compound can clearly be seen and measured. A doctor from the Pathology Clinic - blinded to those cases was responsible for the histological analysis of the slides, discerning - according to the doctor's own criteria - the following findings: resorption of the graft, presence of signs of inflammation and/or infection (neutrophils), neoformation bone, and fibrosis. After this, a second group of researchers, independent and similarly blinded with respect to cases, digitized the slides and measured the mineralized areas occupied by the LBG and the newly formed bone. Micrographs were taken through a microscope (Axiolab E, Carl Zeiss, Gottingen, Germany) coupled with a highdefinition camera (Sony Inc., Japan). The images were inserted into a graphics program (ImageJ 1.40 - National Institutes of Health, USA, http://rsb.info. nih.gov/ij/) for accurate quantification of each area. Histomorphometric parameters were described as pixels by a semi-automatic analysis system; these data were transferred to Excel for Windows, which defined the proportions of each component within the total mineralized area.

Statistical analysis was performed using SPSS 13 for Windows (SPSS Inc. Chicago, IL, USA). Descriptive analyses are presented as mean, maximum, and minimum values for quantitative variables and percentage for qualitative variables.

All of the risks, benefits, and the purpose of the surgery and bone biopsies were made clear to the patients prior to the study, and each was required to sign an informed consent form agreeing with every phase. This study was conducted by the Hip Group of the Orthopedics and Traumatology Clinic, Department of Surgery, Hospital de Clínicas de Porto Alegre (HCPA), Universidade Federal do Rio Grande do Sul (UFRGS), in collaboration with the Pathology Clinic of the institution. This study was approved by the research and ethics committee of the graduate group (GPPG) of HCPA.

\section{RESULTS}

\section{Global analysis}

All demographic data are shown in Table 1. The average age in the group was 51 years (24 to 82), consisting of four $(34 \%)$ male and eight $(66 \%)$ female patients. The average length of hospitalization was 10 (3-38) days and mean follow-up was 49 months (6-115).

\section{Histological analysis}

The slides showed a homogeneous histological pattern when examined microscopically by the pathologist according to their own criteria (Table 2). None of them showed an exacerbated inflammatory response in the periphery of the LBG, which rules out the chance of the body rejecting the foreign body. Neutrophils were only detected in the lamina of patient SG. The presence of varying amounts of fibrosis (Figure 3), signs of a partially resorbed graft (Figure 4), and osteogenesis (Figure 5) were evident in all samples. Avital bone tissue, corresponding to the LBG, which was stained in blue, and vitalized tissue (with nucleated cells) representing newly formed bone, were present in the slides analyzed. The integration between the original bone, the LBG, and the areas of new bone formation are microscopically well defined and occur in large blocks, but maintaining a clear boundary between each (Figure 6). 
Table 1 - Demographic data.

\begin{tabular}{|c|c|c|c|c|c|c|}
\hline Patient & Sex & Age (years) & Procedure & Diagnosis & $\begin{array}{l}\text { Hospitalization } \\
\text { (days) }\end{array}$ & Evolution (months) \\
\hline 1 & 1 & 24 & FO & Femoral pseudarthrosis & 9 & 6 \\
\hline 2 & 1 & 25 & TCA & Talocalcaneal arthrosis & 3 & 59 \\
\hline 3 & 2 & 82 & RTHA & Material wear and tear & 10 & 9 \\
\hline 4 & 2 & 51 & RTHA & Material wear and tear & 9 & 72 \\
\hline 5 & 2 & 64 & RTHA & Material wear and tear & 10 & 43 \\
\hline 6 & 2 & 30 & $\mathrm{FO}$ & Simple bone cyst & 14 & 68 \\
\hline 7 & 2 & 79 & RTHA & Material wear and tear & 38 & 19 \\
\hline 8 & 2 & 55 & THA & Coxarthrosis & 7 & 82 \\
\hline 9 & 2 & 60 & RTHA & Material wear and tear & 12 & 50 \\
\hline 10 & 1 & 45 & TO & Material wear and tear & 3 & 35 \\
\hline 11 & 1 & 43 & FO & Femoral pseudarthrosis & 11 & 16 \\
\hline 12 & 1 & 48 & RTHA & Material wear and tear & 7 & 115 \\
\hline
\end{tabular}

1: Male, 2: Female; TO: Tibial osteosynthesis, FO: Femoral osteosynthesis, EBC: Excision of bone callus, TCA: Talocalcaneal arthrodesis, THA: Total hip arthroplasty, RTHA: revision of THA. HCPA 2011

Table 2 - Histological analysis of slides.

\begin{tabular}{c|c|c|c|c}
\hline & Neutrophils & Fibrosis & $\begin{array}{c}\text { LBG } \\
\text { absorption }\end{array}$ & $\begin{array}{c}\text { New local } \\
\text { bone } \\
\text { formation }\end{array}$ \\
\hline ALL & - & + & + & + \\
\hline JARS 1 & - & + & + & + \\
\hline JARS 2 & - & + & + & + \\
\hline MTRC & - & + & - & + \\
\hline EG & - & + & + & + \\
\hline AMB & - & + & + & + \\
\hline TGG & - & + & + & + \\
\hline AACS & - & + & + & + \\
\hline MB & - & + & + & + \\
\hline SG & + & + & + & - \\
\hline MH & - & + & + & + \\
\hline HJCS & - & + & + & + \\
\hline MAR & - & + & + & + \\
\hline
\end{tabular}

+: present, -: absent. HCPA 2011

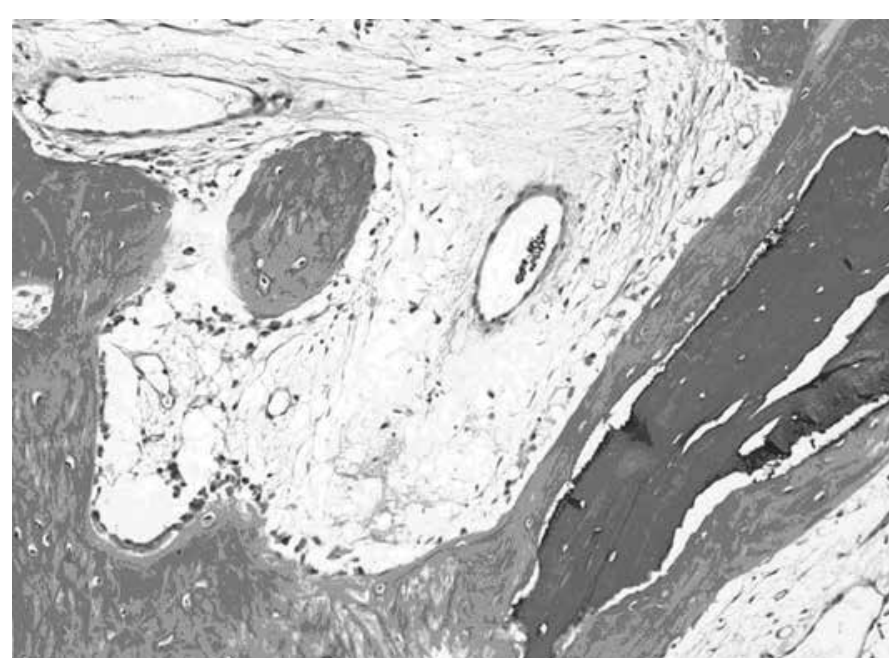

Figure 3 - Fibrosis represented by whitish light areas in the center of the image. 200x magnification. HCPA 2011.

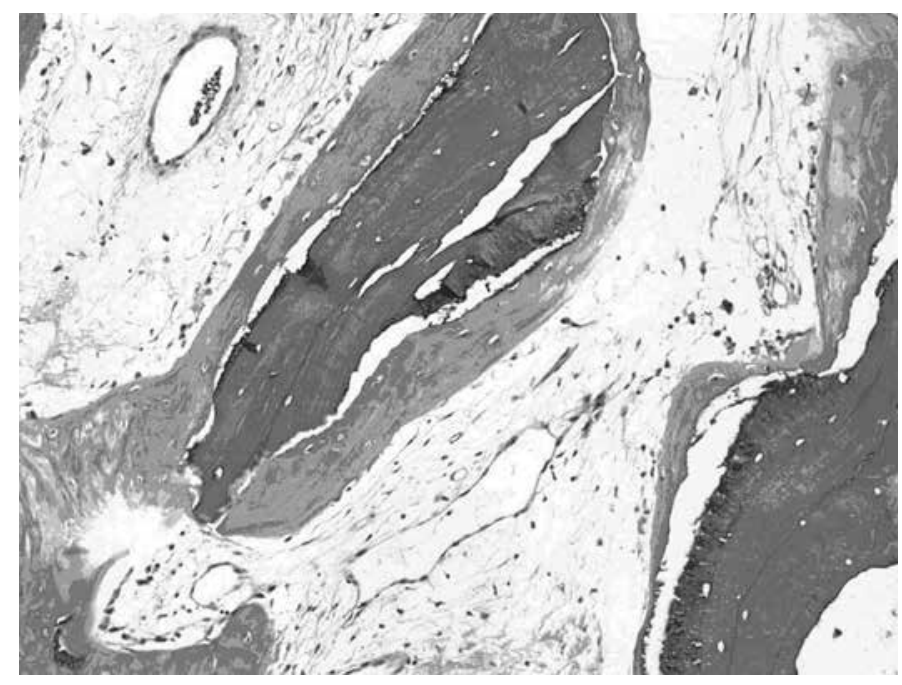

Figure 4 - Lyophilized bovine graft (LBG) (blue areas) surrounded by newly formed bone tissue (pink areas). 200x magnification. HCPA 2011.

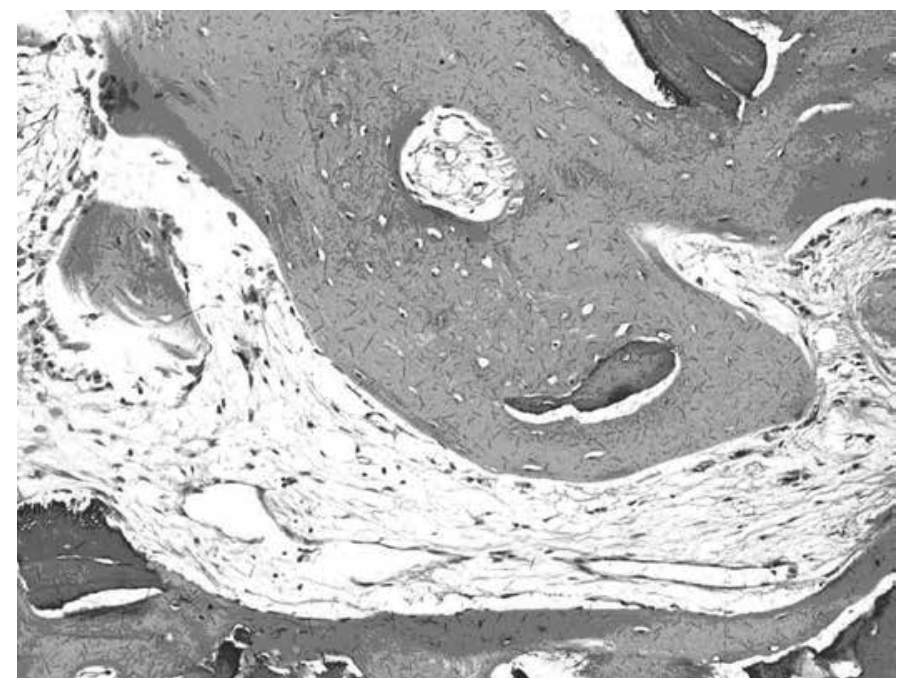

Figure 5 - Partially resorbed (blue areas) of lyophilized bovine graft (LBG) surrounded by newly formed bone tissue (pink areas). 200x magnification. HCPA 2011. 


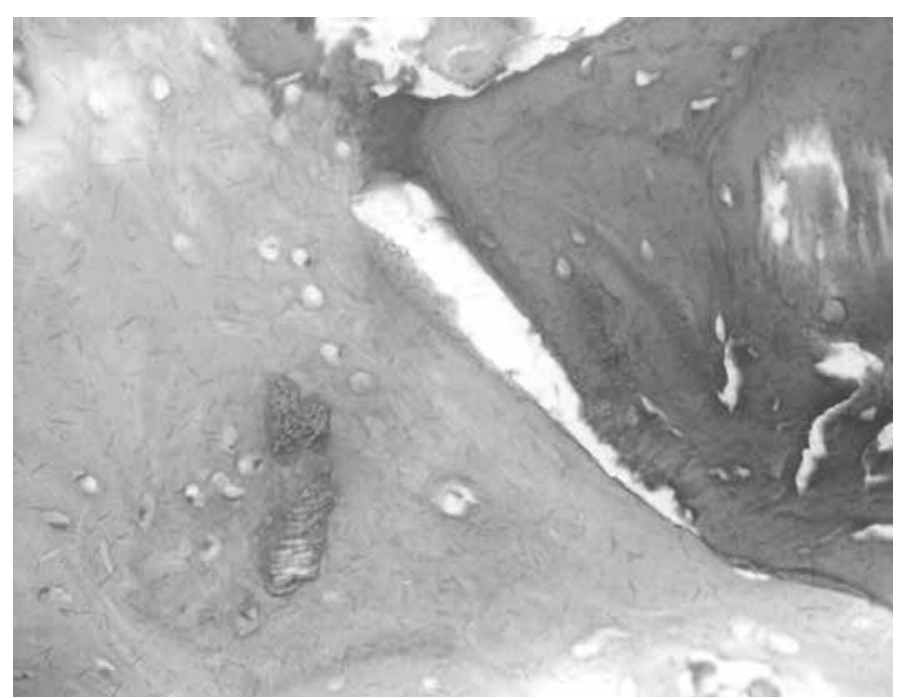

Figure 6 - Well-defined boundaries between the bluish lyophilized bovine graft (LBG) and the pink new bone. 400x magnification. HCPA 2011.

\section{Specific analysis}

The digitized slides showed a mean proportion of $42 \%(13-85 \%)$ of lyophilized bovine graft and $58 \%$ (15-87\%) of new bone formation in relation to the total mineralized area (Table 3). Importantly, two patients showed significant differences in relation to the other samples with a ratio of $\mathrm{LBG} / \mathrm{bone}$ formation of $85 / 15 \%$ and $76 / 24 \%$, and the slides were reviewed, in order to exclude any measurement errors.

Table 3 - Proportions measured.

\begin{tabular}{c|c|c|c}
\hline & LBG & Neoformation & Follow-up* $^{*}$ \\
\hline ALL & $37 \%$ & $63 \%$ & 6 \\
\hline JARS 1 & $34 \%$ & $66 \%$ & 59 \\
\hline JARS 2 & $34 \%$ & $66 \%$ & 59 \\
\hline MTRC & $23 \%$ & $77 \%$ & 9 \\
\hline EG & $32 \%$ & $68 \%$ & 72 \\
\hline AMB & $60 \%$ & $40 \%$ & 43 \\
\hline TGG & $85 \%$ & $15 \%$ & 68 \\
\hline AACA & $26 \%$ & $74 \%$ & 19 \\
\hline MB & $13 \%$ & $87 \%$ & 82 \\
\hline SG & $76 \%$ & $24 \%$ & 50 \\
\hline MH & $47 \%$ & $53 \%$ & 62 \\
\hline HJCS & $38 \%$ & $62 \%$ & 16 \\
\hline MAR & $39 \%$ & $61 \%$ & 115
\end{tabular}

\section{Radiographic analysis}

The radiographs of all patients showed satisfactory consolidation in the perimeter of the graft.

\section{DISCUSSION}

The possibility of using lyophilized bovine graft (LBG) as an alternative to autologous graft in orthope- dic surgery has been investigated for some time, particularly in animal models ${ }^{(6)}$. This study contributes information that is extremely relevant to the use of LBG, produced according to the protocol developed by the main author, in humans, since it demonstrates its osseointegration. Previous studies endorse the use of this LBG both in animals ${ }^{(15,16)}$ and in humans ${ }^{(2,5,18)}$. Meyer et $\mathrm{al}^{(21)}$ brought forth the first data relating to histological osseointegration in relation to $\mathrm{LBG}-$ Tutobone $^{\circledR}$ - in humans. These results were promising, prompting us to evaluate our biopsies and compare the results with those available in the literature.

In our study, which has a design similar to Meyer et $\mathrm{al}^{(21)}$, we found a proportion of $42 \%$ preservation of the LBG and $58 \%$ related to areas of new bone formation compared to the total mineralized area on the slides analyzed in an average period of 49 months. These data are very similar to those presented by this author, who reports having $47 \%$ preservation with Tutobone $^{\circledR}$ and $53 \%$ of new bone formation in the course of 11 months in nine samples.

The presence of LBG in the biopsies allows us to infer that the graft proposed presents undeniable osteoconductivity, being only partially reabsorbed in humans, unlike the complete remodeling which occurs in animals. We found no linear correlation between the duration of follow-up and proportions of $\mathrm{LBG} /$ bone formation in relation to the total mineralized area, and it was not possible to define an exact pattern of behavior, as the sample with nine months of follow-up had a higher rate of neoformed bone than at 62 months. The fact that the slide that had the highest rate of new bone formation $(87 \%)$ was one of the longest durations of follow-up (82 months) is also relevant. Thus, we can say that the LBG used promotes satisfactory, efficient, and durable osseointegration, with human bone tissue during the follow-up period measured.

It is interesting to note that in two samples there were important differences in relation to the others, which were confirmed after further analysis: the LBG/ osteogenesis ratio of $85 / 15 \%$ and $76 / 24 \%$, showing less osteoblastic activity around the graft. There was less bone remodeling in these cases, suggesting some biological or mechanical limiting factor in bone repair. One has Albright syndrome with severe bone and metabolic impairment, which may be a factor related to reduced bone formation. Importantly, even these 
samples showed no difference in the rate of consolidation, or worse clinical outcomes.

This leads us to think that the type and quantity of graft applied are not solely responsible for the capacity for new local bone formation, but that every organism, with its different biological characteristics, affects the response of the osseointegration process. Elucidating this is not the purpose of the present study, but it could justify the behavior. The absence of a foreign body reaction in all slides demonstrates the biocompatibility of the lyophilized bovine graft developed by our group in this study.

The presence of satisfactory osseointegration in radiographic examinations shows that the $\mathrm{LBG}$ in this study presents a visual pattern similar to other commonly used types of grafts. Previous experiments showed full osseointegration in $75.8 \%$ after six months and nearly all cases at 12 months $^{(21)}$.

We did not use a control group, since the study design did not allow for it. The objective of the study is to evaluate the histological behavior of LBG in humans and not to discuss its superiority.

\section{CONCLUSION}

This is the first histological study using lyophilized bovine graft (LBG), produced according to the protocol developed by the main author, in humans. The results show that this graft had satisfactory biocompatibility and did not harm the patients. Additionally, it showed good osteoconduction and integration in an average follow-up period of 49 months, fulfilling the role that was expected of it.

The results obtained are promising and contribute to strengthening the role of the LBG as a treatment option for dental and orthopedic surgeries that require some type of graft to fill bone defects.

\section{REFERENCES}

1. Finkemeier CG. Bone-grafting and bone-graft substitutes. J Bone Joint Surg Am. 2002;84(3):454-64.

2. Rosito R, Galia CR, Macedo CA, Moreira LF, Quaresma LM, Palma HM. Acetabular reconstruction with human and bovine freeze-dried bone grafts and a reinforcement device. Clinics (Sao Paulo). 2008;63(4):509-14.

3. Lexer E. Joint transplantations and arthoplasty. Tradução de Frank H'Doubler. Surg Gynecol Obstet. 1925;40:782-809.

4. Oliveira RC, Sicca CM, Silva TL, Cestari TM, Oliveira OT, Buzalaf MAR. Efeito da temperatura de desproteinização no preparo de osso cortical bovino microgranular. Avaliação microscópica e bioquímica da respota celular em subcutâneo de ratos. Revista FOB. 1999;7(3/4):85-93.

5. Galia CR. Enxertos ósseos liofilizados impactados humanos e bovinos em revisão de artroplastia total de quadril [tese]. Porto Alegre/RS: Universidade Federal do Rio Grande do Sul; 2004.

6. Sugihara S, van Ginkel AD, Jiya TU, van Royen BJ, van Diest PJ, Wuisman $\mathrm{PI}$. Histopathology of retrieved allografts of the femoral head. JBone Joint Surg Br. 1999;81(2):336-41.

7. Godwin L. Tissue banking and allograft transplantation. [periódico online]. 2000 Disponível em: www.iscpubs.com/articles/abl/b0006god.pdf

8. Buck BE, Malinin TI. Human bone and tissue allografts. Preparation and safety. Clin Orthop Relat Res. 1994;(303):8-17.

9. Kreuz FP, Hyatt GW, Turner TC, Bassett AL. The preservation and clinical use of freeze-dried bone. J Bone Joint Surg Am. 1951;33(4):863-73.

10. Autograft, allograft, and xenograft. Disponível em: www.pharmacy.wisc.edu/ courses/718-430/handouts/ tisgraft.pdf

11. Seiler JG 3rd, Johnson J, Hand G, Microsurgery Clinic. Iliac crest autogenous bone grafting: donor site complications. Journal of the Southern Orthopedic Association Disponível em: www.medscape.com/viewarticle/410431.

12. Lind M, Krarup N, Mikkelsen S, Horlyck E. Exchange impaction allografting for femoral revision hip arthroplasty: results in 87 cases after 3.6 years' follow-up.
J Arthroplasty. 2002;17(2):158-64.

13. Heliotis $M$, Tsiridis EE. Fresh frozen bone in femoral impaction grafting: can developments in bone regeneration improve on this? Med Hypotheses. 2001;57(6):675-8.

14. Palmer SH, Gibbons $\mathrm{CL}$, Athanasou NA. The pathology of bone allograft. J Bone Joint Surg Br. 1999; 81(2):333-5.

15. Galia CR, Macedo CAS, Rosito R, Mello TM. Uso de enxerto ósseo homólogo e heterólogo em diáfise femural de ratos: comparação entre enxerto ósseo congelado e liofilizado. Rev Bras Ortop. 2005;40:141-6

16. Galia CR, Macedo CA, Rosito R, Mello TM, Camargo LM, Moreira LF. In vitro and in vivo evaluation of lyophilized bovine bone biocompatibility. Clinics (Sao Paulo). 2008; 63(6):801-6.

17. Williams D. Revisiting the definition of biocompatibility. Med Device Technol. 2003;14(8):10-3.

18. Nuss KM, Auer JA, Boos A, von Rechenberg B. An animal model in sheep for biocompatibility testing of biomaterials in cancellous bones. BMC Musculoskelet Disord. 2006;7:67.

19. Pearce AI, Richards RG, Milz S, Schneider E, Pearce SG. Animal models for implant biomaterial research in bone: a review. Eur Cell Mater. 2007;13:1-10.

20. Conn RA, Peterson LFA, Stauffer RN, Ilstrup D. Management of acetabular deficiency: Long-term results of bone grafting the acetabulum in total hip arthroplasty. Orthopaedics Trans. 1985;9:451-4

21. Meyer S, Floerkemeier T, Windhagen H. Histological osseointegration of Tutobone: first results in human. Arch Orthop Trauma Surg. 2008;128(6):539-44.

22. Galia CR, Macedo CA, Rosito R, Mello TM, Camargo LM, Moreira LF. Femoral and acetabular revision using impacted nondemineralized freeze-dried bone allograft. J Orthop Sci. 2009;14(3):259-65.

23. Kakiuchi M, Ono K, Nishimura A, Shiokawa $H$. Preparation of bank bone using defatting, freeze-drying and sterilisation with ethylene oxide gas. Part 1. Experimental evaluation of its efficacy and safety. Int Orthop. $1996 ; 20(3): 142-6$ 